University of Rhode Island

DigitalCommons@URI

Open Access Master's Theses

2016

\title{
A Text Message Intervention to Increase Awareness of Sexual Assault on Campus
}

Ximena Chiriboga

University of Rhode Island, ximena_chiriboga@hotmail.com

Follow this and additional works at: https://digitalcommons.uri.edu/theses

\section{Recommended Citation}

Chiriboga, Ximena, "A Text Message Intervention to Increase Awareness of Sexual Assault on Campus" (2016). Open Access Master's Theses. Paper 901.

https://digitalcommons.uri.edu/theses/901

This Thesis is brought to you for free and open access by DigitalCommons@URI. It has been accepted for inclusion in Open Access Master's Theses by an authorized administrator of DigitalCommons@URI. For more information, please contact digitalcommons-group@uri.edu. 


\section{A TEXT MESSAGE INTERVENTION TO INCREASE AWARENESS OF SEXUAL ASSAULT ON CAMPUS}

\section{By}

XIMENA CHIRIBOGA

A THESIS SUBMITTED IN PARTIAL FULFULLMENT OF THE REQUIREMENTS FOR THE DEGREE OF MASTER OF SCIENCE

IN

DEVELOPMENTAL SCIENCES 
MASTER OF SCIENCE IN DEVELPMENTAL SCIENCES

\author{
$\mathrm{OF}$ \\ XIMENA CHIRIBOGA
}

APPROVED:

Thesis Committee: Karen McCurdy

Sue Adams

Paul Bueno de Mesquita

Nasser H. Zawia

DEAN OF THE GRADUATE SCHOOL

UNIVERSITY OF RHODE ISLAND

2016 


\begin{abstract}
Sexual assault on college campuses is an important problem for the college community. In order to increase awareness in college students about this problem, a randomized 4-week text message campaign was implemented in the University of Rhode Island's Psychology 113 class. To analyze the impact of the intervention, twosample t-tests were conducted on the variables of interest. Results showed no significant impact of the campaign on two measures of awareness, Gender-Specific Barriers to Bystander Behavior Items (Burns, 2009) and College Date Rape Attitude Survey (Lanier \& Green, 2006). When measuring the impact conditional on demographics, the results remain the same. These results can inform educator, policy makers, college students and other member of the college community about the limitations of this type of intervention.
\end{abstract}




\section{Acknowledgment}

I would like to acknowledge many individuals who have been very important in this journey, called graduate school. First my advisor Karen McCurdy, that was a very important piece of this journey. All her patience and dedication helped me to achieve this goal. Also Sue Adams and Paul Bueno de Mesquita, with whom this project could not be what it is today. Also I would like to acknowledge Candy for all her support and great encouragement in this ride $:$. 
Table of contents

Abstract ........................................................................................................ ii



Table of contents .................................................................................... iv

List of tables ....................................................................................... vi

List of figures ......................................................................................... vii

Introduction ................................................................................................ 1

Justification for and Significance of the Study ............................................... 1

Sexual Assault prevention programs........................................................................... 3

Text message health interventions ......................................................................... 7

Theoretical framework: Protection Motivation Theory …………............................ 11







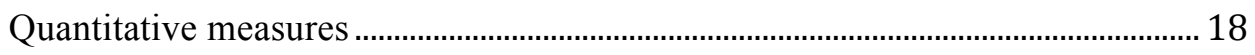

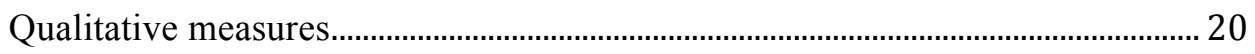

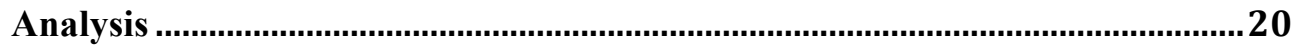

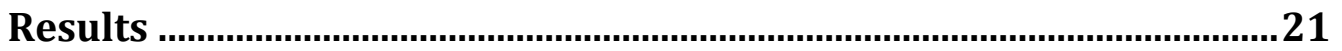

Description of the sample

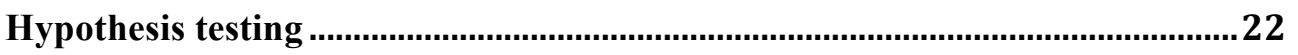




Appendix 1 Gender-Specific Barriers to Bystander Behavior (Burns,

2009)

Appendix 2 College Date Rape Attitude Survey (Lanier \& Green,

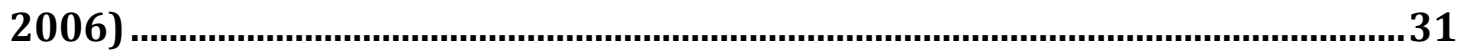

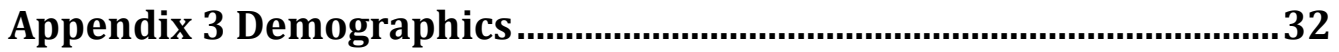

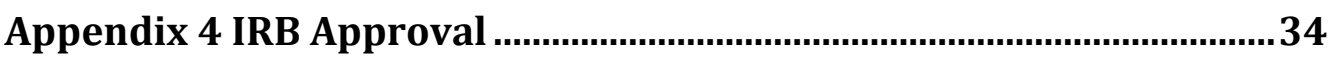

Appendix 5 Informed Consent .................................................................36

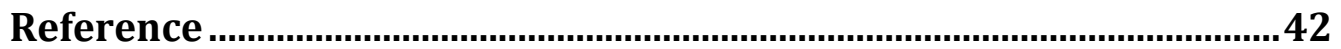




\section{List of tables}

TABLE 1 DESCRIPTIVE STATISTICS …........................................... 39

TABLE 2 TREATMENT VS CONTROL............................................ 40

TABLE 3 ANALYSIS OF THE IMPACT OF THE INTERVENTION. 41 


\section{List of figures}

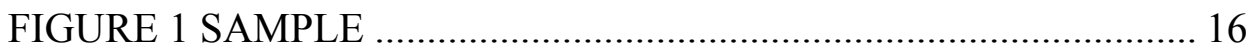




\section{Introduction}

Sexual assault, defined as nonconsensual sexual contact (Cantor \& Fisher, 2015), is a common situation among college students and more prevalent among them than in the general population (Anderson, \& Whiston, 2005; Fisher, Cullen, \& Turner, 2000). The majority of the victims of sexual assault in the United States are female and/or members of the LGBT community ages 18 to 24 (Sinozich, \& Langton, 2014). College students are the most vulnerable population for sexual assault crimes. One in five female college students was a victim of sexual assault during college (Force, 2014). Sexual assault can have many consequences in the victim's life that can range from psychological to physical and with different levels of severity (Krebs, Lindquist, Warner, Fisher, \& Martin, 2007). Given this reality, policy makers and college authorities need to create new and better programs to prevent sexual assault on college

campuses. To address this issue, this study will implement and evaluate the impact of 4-week text message based intervention on increasing the awareness of sexual assault among college students. The hypothesis for this study is the following: the text message intervention will have a positive impact on awareness of sexual assault on college students.

\section{Justification for and Significance of the Study}

College sexual assault prevention programs are important to the students in order to create awareness and decrease the incidence of this problem (Söchting, Fairbrother, \& Koch, 2004). Giving information about the main sexual assault risk factors to the students can help them develop new strategies to prevent it. The 
following five sexual assault risk factors are the most robust empirical findings in the literature of sexual assault among college students.

First, alcohol consumption among college students is higher than among noncollege student rates; in particular, $40 \%$ of college students can be considered heavy drinkers (Cooper, 2002; Dawson, Grant, Stinson, \& Chou, 2004). For this reason, college students are at higher risk of sexual assault. Alcohol over consumption can reduce the victim's ability to give consent and to take care of her/his own safety (Schwartz, Milteer, \& LeBeau, 2000).

Second, students lack of knowledge of the use of drugs (legal or illegal) that facilitate sexual assault. Usually known as drug-facilitated sexual assault, this is a common method used to deceive the victim into consuming drugs to impair his/her ability to defend his/her self (Cantor, \& Fisher, 2015). Perpetrators use these drugs as they act very fast in the victim, leaving almost no time for reaction. They are very difficult to perceive when dissolved in drinks or food as they are usually flavorless, colorless and odorless (Schwartz et al., 2000). The symptoms that the victim will experience include dizziness, loss of inhibition and consciousness, and confusion (Schwartz et al., 2000).

Third, freshmen are at highest risk of being sexually assaulted as compared to other college populations (Cantor \& Fisher, 2015). The vulnerability of this population is explained by the inexperience of its members and because it is an intense social exploration stage of college life, where they try to meet new people, yet the college freshmen do not have a stabilized social support system (Cantor, \& Fisher, 2015). 
Moreover, the vulnerability of being sexually assaulted consistently decreases as one progresses in college life (Cantor \& Fisher, 2015).

Fourth, the lack of knowledge about the typical perpetrator can increase one's risk. Most victims of sexual assault know their offenders before the incident happened. As a result, 9 out of 10 victims had some type of relationship with the offender such as romantic, friendship or professional (Fisher et al., 2000). It is important to warn college students to not lower their level of precaution when interacting with acquaintances.

Fifth, sexual assault is more likely to happen in certain locations, such as residences, dorms, fraternities and some private settings (Fisher et al., 2000). Also places like bars or parties are where offenders look for victims (Söchting et al., 2004). About $60 \%$ of sexual assault cases are reported to happen in the victim's residence (Fisher et al., 2000).

Sexual assault prevention programs are designed to increase awareness about sexual assault among college students, male and female. The interventions usually take about 2 hours and occur in one session (Breitenbecher, 2001). This is a common limitation of the existing interventions, and there is a little research on long-term interventions that can provide opportune and relevant support to prevent sexual assault (Breitenbecher, 2001; Sinozich \& Langton, 2014).

\section{Sexual Assault prevention programs}

All sexual assault prevention programs that are reviewed here deliver almost

the same information, but use different modalities such as workshops, video presentation or online intervention (Anderson, \& Whiston, 2005; Breitenbecher, 2001). The information provided in the interventions is based on the previous 
mentioned risk factors with the idea of educating the students about sexual assault. Interventions with positive effects are giving vital information that can be used in dangerous situations (Anderson \& Whiston, 2005; Breitenbecher, 2001). Most programs are design to be delivered to the population in a one-time intervention.

For example, Foubert, Langhinrichsen-Rohling, Brasfield, \& Hill (2010) evaluate a program called "The Women's Program" that consisted of a one-time workshop about identification of male predator techniques and also how to intervene in a sexual assault risky situation as a peer bystander. The intervention used different materials such as discussion, videos and speakers. The participants of this experiment were 279 women, the majority identified as freshmen, with 90 of the sample as part of the control group. The instruments used to measure the impact of the intervention were the Illinois Rape Myth Acceptance Scale Short Form (IRMA-SF), Bystander Efficacy Scale (BES) and the Bystander Willingness to Help Scale (BWHS). Participants filled the instruments when they arrived to the classroom and again one when the intervention finished, the treatment group self-reported significant gains on the BES and BWHS, and also experienced a significant decline in their IRMA-SF scores as compared to control group. This intervention did not measure long-term effects. Some limitations of this intervention are the lack of data on long term outcomes, the population used were part of one subgroup in a specific university the results may not be generalized to university population in the USA and finally the data were self-reported.

Banyard, Moynihan, \& Crossman (2009) used a 90 minute in-person educational workshop called "Bringing the Bystander" to increase bystander 
intervention among college leaders. The participants of this program were 196 men and women who were part of the college leaders program and students working at the student center. The majority of the population in this research was juniors. All the participants took a pre and posttest, after and before the intervention to evaluate the impact. The measures used in this intervention were the BSE, IRMA, BWHS, pros to bystander behavior, cons of bystander behavior and pros minus cons to bystander behavior. The participants in the program showed significant positive effects on these measures related to bystander intervention, despite the fact that students were knowledgeable about the topic as they were part of the college leaders group. Some limitations of this study were the lack of control group and that the post survey was collected right after the intervention, which limits the long term impact evaluation of the program.

Also, there are other programs that are hosted in a different setting like "Take Care" an online format designed by Kleinsasser, Jouriles, McDonald, \& Rosenfield, (2015). This program is the first online intervention for women and men, created to increase bystander intervention in sexual assault situations. Ninety-three college students participated in this intervention. They were randomly assigned to a control or treatment group. Participants complete a pretest, posttest, and 2-month follow up, and the measure used was 51-item Bystander Behaviors Scale and efficacy for intervening. The intervention took 20 minutes and included 3 short videos with vignettes about how to prevent and intervene in a sexual assault situation. Participants schedule an appointment with the researcher to go to the laboratory to see the video, the researcher took participants cellphones to avoid distractions. The main interest of Kleinsasser, et 
al., (2015) was to create an intervention that provided students with a tool that can be accessible according to their schedule, as the authors realize that it is difficult to gather all the college community one day for an intervention. The intervention showed significant positive effects among participants by increasing scores on the Bystander Behavior Scale not only in the post-test but also at the two-month follow-up (Kleinsasser, et al., 2015). Some limitations mentioned by the authors were the lack of diversity in the sample, and the limitation of the measurements as these are not able to address different levels of change in bystander behavior. Also participants were mandated to see the intervention from just one laboratory, making it less applicable to the general population that may not have time to schedule this intervention.

Some of the main limitations of the interventions are the need for boosters to preserve the impacts in the long term, as most of the interventions are delivered once, which make it difficult to address all the complex information about sexual assault prevention. Another limitation is the equipment (e.g., computer and internet). The college population has less access to these technologies in comparison to cellphones, $96 \%$ of undergraduate students own a cellphone in comparison to the $88 \%$ of the same population that own laptop computers (Smith, Rainie, \& Zickuhr, 2011). In the case of sexual assault prevention interventions, most of them are provided at the beginning of the semester in the freshmen year, when students are not familiar with the college environment and therefore may not be completely attentive to the intervention.

These three sexual assault prevention interventions reviewed above show statistically significant positive impacts irrespective of the format. The programs provide information to increase bystander intervention and to decrease misconceptions 
about sexual assault, which are an important part to prevent sexual assault on college campus as students may not be aware of these risk factors and for that reason may get involved in dangerous situations (Banyard et al., 2009; Breitenbecher, 2001; Foubert, et al., 2010; Kleinsasser, et al., 2015). However, the existing interventions have some shortcomings that can be improved upon by the text message campaign proposed here. According to Foubert, et al. (2010), they are time consuming and complicated to organize which often results in a one-time intervention format. In the same line, lack of follow-up and reinforcement could be crucial to long-term success.

\section{Text message health interventions}

Text message-based health promotion interventions have been recently used for improving health or behavior in different settings and have been found to have positive effects (Hall, Cole-Lewis, \& Bernhardt, 2015). Short text messages to a cellphone can deliver information regarding a topic of interest in order to encourage changing a predetermined behavior established at the beginning of the program, achieve a goal or provide health information (Fjeldsoe, Marshall, \& Miller, 2009; Gold, Lim, Hellard, Hocking, \& Keogh, 2010; Hall, et al., 2015; Obermayer, Riley, Asif, \& Jean-Mary, 2004).

The results of such interventions may be more positive than one-time workshops for three reasons. First cellphones are technological devices with more users even than Internet. There are at least twice as many cellphone users than Internet users (Fjeldsoe, et al., 2009; Gold, et al., 2010), which make this technology very accessible. For example, $96 \%$ of undergraduate college students report having a cellphone (Smith, et al., 2011). Also their use does not require a lot of training and people of all ages know how to use them (Gold, et al., 2010; Hall, et al., 2015). 
Second, the equipment (cellphone) is less expensive than other technological devices such as computers, thus more people are able to buy them. Finally cellphones are small and easy to carry wherever the person moves. People have access to cellphones all the time, which make it easy to check the messages immediately when they arrive (Obermayer, et al., 2004), providing the intervention when the person needs it.

Text messaging health promotion interventions nowadays are inexpensive and computer programs can be programmed to deliver text messages automatically. Companies that provide massive text message service usually have promotions that allowed the user to send more messages at lower cost, with an average of 0.02 usd per text message. This makes it easy to create an intervention and deliver it without concern about the cost of organization (physical facility, food, promotion of the program, and miscellaneous) (Fjeldsoe, et al., 2009; Gold, et al., 2010; Obermayer, et al., 2004). In addition, text message interventions do not have any time constraints in terms of delivery, as people can receive the messages were they potentially need or want them, avoiding the trouble of setting up a time when all the participants are physically available and also a time when the intervention is delivered. One of the troubles with traditional sexual assault interventions is that people get the intervention at a certain time when they probably cannot use it and, by the time they need it, they may not remember all the details (Fjeldsoe, et al., 2009; Gold, et al., 2010). Also text messages can deliver sensitive information in a private manner to help the recipients feel comfortable about the information they are receiving which might make them more open to engage in the intervention (Gold, et al., 2010). 
These interventions can engage with large amounts of people at the same time without constraints (Gold, et al., 2010). This is important in terms of being able to provide the same type of intervention in a limited amount of time to a big group of participants, which text messages are able to provide. Finally, text messages can create a personal connection with the people in the intervention as they are delivered to their own cellphones (Fjeldsoe, et al., 2009; Gold, et al., 2010; Obermayer, et al., 2004). Some text message health improvement campaigns had positive effects on outcomes. Obermayer, et al., (2004) developed a web and text message intervention to help current smokers to quit. The program recruited 46 regular smokers from college, ages 18 to 26 years old. Participants first registered their information on a website that was able to create an intervention tailored for each participant based on the information previously obtained. The intervention was delivered to the participant's cellphone to make it more personal and also to provide the information when the participant needed it based on the website information. Participants in the program completed three measures: 7-day smoking reconstruction, Nicotine-Dependence Syndrome Scale and program questioner. Results showed a significant decrease in the smoking rates and quitting attempts from the participants. The limitations of this intervention were the lack of comparison group, making these results not conclusive because other factors may have caused the positive effect, and also some participants did not complete the web survey because of time constraints.

Another example of text message health promotion is the work by Gold et al., (2010). Researchers conducted a focus group to better understand the positive effects of a 12-week text message intervention to deliver sex education to 676 adolescents and 
young adults ages 16 to 29 years old. Participants in the text message intervention were contacted to be part of the focus group. Researchers offered monetary rewards to the participants in the focus group and a total of 141 agreed to be part of it. The results of the focus group showed that the reason why a sex education text message intervention might be useful is because the participants felt more comfortable receiving this information on a private device that they can check any time they need it. Also, the idea of having "taboo" information delivered in a more informal way made them feel relaxed while reading the message. Participants mentioned that informal and funny messages were forwarded to close friends in order to share this valuable information. The text messages delivered known information as reminders, and provided new information. Findings suggested that the text messages decreased participant anxiety of testing for sexually transmitted infections as they reported. One limitation of the intervention was bias on the participants, because they agreed to be part of the focus groups and still were part of the text message intervention.

Text messages have been use to increase healthy habits. A program designed by Cocosila, Archer, Haynes, and Yuan (2009) was created to increase Vitamin C intake. A sample of 102 subjects, 18 years and older, were randomly selected from an undergraduate level class to participate in the program. The participants were assigned to a control and treatment group after completing a pre survey; the measures used in this program were self-reported. Both groups receive Vitamin C tablets but only the treatment group received a text message to remind and encourage the intake of the Vitamin C. The result of this program indicated an increase in the intake of Vitamin C 
for the control and treatment groups, but a higher level of increase for the treatment group, although the difference was not statistically significant.

Overall text message interventions on improving health have positive effects on the population of interest, showing a new, non-costly and time efficient way to provide information. These interventions may be a better way to communicate with the population of interest and to have a positive impact on them.

\section{Theoretical framework: Protection Motivation Theory}

The theoretical basis for the hypothesis, that a the text message intervention will have a positive impact on awareness of sexual assault on college students, is the Protection Motivation Theory (PMT), created by Rogers in 1983. The PMT explains how our protective behavior is based on four principles: perceived susceptibility to the risk, perceived severity of the risk, self-efficacy when executing the risk reduction behavior, and response efficacy of the behavior (Maddux, \& Rogers, 1983). The two first principles represent the "perception of the threat" and the other two are the “coping efficacy" (Floyd, Prentice-Dunn, \& Rogers, 2000). Also the theory states that people can participate in healthy behaviors not only to be healthy by also to prevent the interpersonal and social risks that unhealthy behaviors can have (Pechmann, Zhao, Goldberg, \& Reibling, 2003). The PMT is used to change, improve and create behaviors especially in the in the health area (Floyd et al., 2000).

The focus on increasing awareness of sexual assault risk factors such as alcohol consumption, lack of knowledge of the use of drugs (legal or illegal) to facilitate sexual assault, vulnerable college population, perpetrator characteristics, and frequent location of sexual assault, targets the first mechanism of PMT "perception of the threat". Students may be able to identify potentially dangerous sexual assault 
situation. The text messages could address these risk factors providing a remainder for the participants with the aim to improve their "perception of the threat." The "perception of the threat" is concentrated on the source of the problem where the severity and vulnerability of the situation is analyzed.

Also, the information provided on strategies to prevent sexual assault such as looking for help when needed in a potential dangerous situation, bystander intervention, and active discussion of risk factors with peers targets the second mechanism "coping efficacy". This information will better prepare the intervention participants to take action in a possibly sexual assault situation not only for them but also for the people around. The "coping efficacy" refers to the ability of the individual to prevent or eliminate the dangerous situation. The information provided in the text messages was designed to avoid triggering bad experiences, memories or revictimization of participants using PMT, as sexual assault may be a delicate topic for some participants.

Previous studies have applied the PMT to prevention programs. Pechmann et al. (2003) conducted research to understand how 194 television antismoking advertisements impacted adolescents based on PMT. The study was divided in two parts. In the first part, a group of 45 adolescents coded the antismoking campaigns, creating 7 themes related to PMT. In the second part, 1667 adolescents recruited from local high schools were randomly assigned to 8 groups. Seven of the eight groups watched one videotape randomly assigned from the previously coded antismoking campaign videotapes. The eighth group was the control group assigned to watch a videotape about drunk driving. Participants completed a questionnaire with four 
measures including behavioral intentions, healthy risk perceptions, social risk perceptions and efficacy, cost, and benefit perception. At the end, three of the seven themes impacted adolescents' smoking intentions in comparison to the control group. For example, the "disease and death message theme" showed diseases of people who smoke, reflecting the concept of "risk severity." Even though the program focused only on the intention not to smoke and not the smoking behavior, it is important to understand how adolescents get information from television ads.

Another example of PMT is the research by Prentice-Dunn, Mcmath, and Cramer (2009). The authors conducted a study about sun protective behavior with 254 female undergraduate college students from a psychology class. Participants were presented with an essay about sun exposure consequences in different levels of severity. High threat level presented essays that included photos of severe skin lesions in contrast with the low threat level that presented beneficial information about sun exposure. Also, high coping essays emphasize the importance of avoiding sunbathing and use of sunscreen, and the low coping essay was designed to mention the ambiguity of sunscreen protection levels and the troublesomeness to use it. To assess the impact of the intervention, the authors evaluated stages of change, PMT variables such as response efficacy, and behavioral intentions and requests after the intervention and ten days later. The authors found a significant positive impact on the readiness to change in the participants who had the information from the high threat and high coping essays. These results indicate that participants may pay more attention to the information if it is more severe. The inclusion of emotional information in the essays may have a bigger impact in the population as this component may motivate them to 
take actions. The authors also found that people tend to skip prevention information in magazine pages when there is information about skin cancer. For that reason, there is a need to send this information in a more direct and personalized way so that participants pay more attention.

The PMT theory implies that there could be a positive impact of the text message intervention to increase sexual assault awareness on college campus. The content of the messages draws attention to the threat of sexual assault on campus helping students improve their estimation of the probability of this event conditional on several risk factors and also providing information about useful recourses. The intervention utilizes this theory to promote sexual assault awareness on college campus using text messages to increase, simplify and provide timely information to improve the decision process for the students.

\section{Methods}

The following research is an experimental study consisting of a four-week text message information campaign aimed at improving sexual assault awareness among 76 college students. The data were collected after the fourth week with an online survey delivered at the participant's personal cellphone via text message. The impact of the campaign was assessed at the level of the whole sample and within subgroups that were created based on the collected demographic data.

In order to test the influence of the text message intervention on the outcomes of interest, Gender-Specific Barriers to Bystander Behavior Items (Burns, 2009) and College Date Rape Attitude Survey (Lanier \& Green, 2006), a two-tailed two sample t-test was performed under the hypothesis there is no impact of the intervention. Also, 
a one-tailed two sample t-test was performed under the hypothesis that the impact is less than or equal to zero. Also an exploratory analysis about the impact of the intervention on the subgroups of interest (gender, year in college, relationship status and sexual assault prevention class participation) was performed using a two-tailed two sample t-test.

\section{Procedures and Sample}

The population involved in the experiment was University of Rhode Island students from 2 sections of a psychology 113 class taught in the spring semester of 2016. This is a convenience sample. To recruit the sample, the two sections were visited by the researcher who provided a brief description of the intervention to the students and obtained their informed consent (Appendix 5). The study enrollment was incentivized using class credits.

The study was approved by the IRB and all the protocols were followed during the process (Appendix 4). Data were collected anonymously with an online survey and the informed consent forms were stored in a secure place at the Transition Center. There were 155 volunteers between the two sections; 77 were placed into the control group and 79 into the treatment using randomization. The randomization process used a random numbers generator in Microsoft Excel. For each subject, a number between 0 and 1 was drawn with uniform probability those that had assigned number greater or equal to 0.5 were assigned to the treatment group.

The intervention sample is presented in figure 1. The dropout rate (participants who stopped the intervention before it was over) from the study was $4 \%$.

Unfortunately, there is no data available for this group as they did not complete the survey. The full study response rate from the final survey was 52\% (38 participants 
from the control group and 43 participants from the treatment group). Further, $9 \%$ of the sample failed to complete one question; an average was calculated to substitute these missing responses. Lastly $6.2 \%$ of the final sample were contaminated (someone from the treatment group forwarded the messages to someone in the control group), so the final sample consisted of 34 participants in the control group and 42 participants in the treatment group.

\section{Figure 1 Sample}

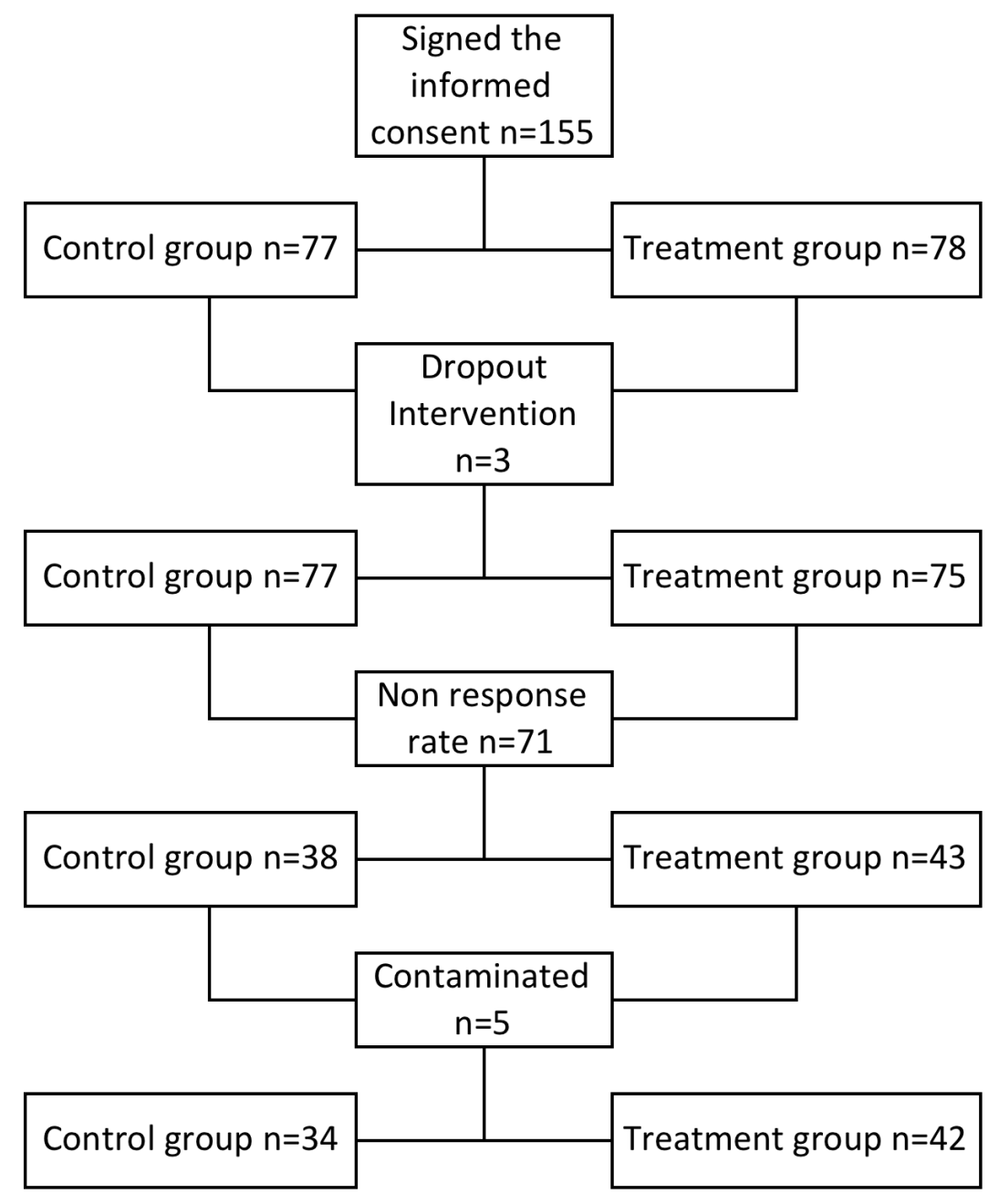


To protect the privacy of the participants in the study, two separate links were sent, one for the control group and one for the treatment group with the same survey. This exercise helped to identify each of the groups without any personal information connected to the survey. For a four-week period, the treatment group received two text messages per week in the afternoon, as the majority of the sexual assault incidents happen at social events usually at night (Söchting et al., 2004). The content of the text messages were about sexual assault general facts, risk factors, and tips to prevent it. The text messages were the following:

1) Sex without consent isn't sex. It is rape. For more information visit: https://www.notalone.gov

2) Sexual assault perpetrators use drugs that have no odor, color or flavor. Know your limits, if $u$ or a friend doesn't feel right after a drink get help. Resources: http://web.uri.edu/womenscenter/resources/

3) Sexual assault is more likely to happen when a student is incapacitated by alcohol or drugs as they take away the ability to give consent. If you see someone in this situation take action. Resources: http://web.uri.edu/womenscenter/resources/

4) 9 out of 10 sexual assault victims know their offenders. Keep this in mind when you are out today and remind your friends. Resources: http://web.uri.edu/womenscenter/resources/

5) 6 out of 10 sexual assault cases occurred at the victims' residence, so think twice before inviting someone over and speak out if you see your friends doing this. Resources: http://www.dayoneri.org 
6) New in college? Freshmen students are at highest risk of being victims of sexual assault. Keep an eye on your friends especially if they are freshmen. Resources: http://www.nsvrc.org/saam/preventing-sexualviolence-campus

7) Bystander intervention can help stop sexual assault. Do your part and help a friend or a stranger. Resources: http://itsonus.org

8) You can reduce the odds of sexual assault happening, remember the facts and get ready to take actions. Thanks for participating.

The sample characteristics are the following: $85.2 \%$ are 20 years old and the rest of the subjects are 21-26 years old. The participants identified as female were $67.9 \%$ and the rest as male. Also $67.5 \%$ of the participants are freshmen. The majority of the sample reported their race/ethnicity as white $(75.5 \%)$.

\section{Measures}

The following measures were used in the study: Gender-Specific Barriers to Bystander Behavior Items (Burns, 2009), College Date Rape Attitude Survey (Lanier \& Green, 2006), demographic and satisfaction questionnaire. This information was collected after the four-week text message intervention and was self-reported by the participants.

\section{Quantitative measures}

Gender-Specific Barriers to Bystander Behavior Items (Appendix 1) was created by Burns (2009). The instrument has 18 items, 8 for females, 8 for males and 2 for both sexes. The first four questions of each section (female and male) are designed to assess bystander intervention related to female friends; the remaining four questions are about bystander intervention related to both sexes. The instrument was applied to 
the whole sample indistinctively of their gender. The instrument uses 7-point response scales, ranging from 1=Strongly Disagree, 2=Disagree, 3=Somewhat Disagree, 4=Neither Agree nor Disagree, 5=Somewhat Agree, 6=Agree, $7=$ Strongly Agree. The Cronbach's alpha calculated for the total sample was .90 , which is very similar to the one calculated by Amar, Sutherland, \& Laughon (2014) that was .89. This measure is connected to "coping efficacy" in the PMT because it measures the willingness to take action after a threat was perceived.

\section{College Date Rape Attitude Survey (Appendix 2) was created by Lanier \&} Green (2006). The measure has 24 questions and 5-point Likert response scales. $1=$ strongly agree, $2=$ agree, $3=$ neutral, $4=$ disagree and $5=$ strongly disagree. This measure appraises attitudes associated with sexual assault risk factors for adolescents and young adults (Lanier, \& Green, 2006) and is related to the "perception of the threat" in the PMT. The Cronbach's alpha calculated for this instrument was .63, somewhat lower than .74 calculated by Lanier, \& Green, (2006). Other studies such as Amar, et al., 2014 found a Cronbach's alpha for their study of .894 with a population of 220 college students, which suggests that the number of participants in the study may impact the Cronbach's alpha.

Demographic Questionnaire (Appendix 3) As sexual assault knowledge of risk factors and vulnerability may be related to demographic characteristics, data was collected on: age (measured in years), gender (female, male, and other), year in college (freshmen, junior, sophomore, and senior), race/ethnicity (American Indian or Alaska Native, Asian, Black or African American, Hispanic/Latino, Native Hawaiian or other Pacific Islands, White, Multiracial, and Other), place of living (Parents house, 
on campus residence, Greek housing, of campus, and other), dating status (single, dating, married/living together, divorce, widowed, and other), and previous sexual assault prevention class participation (yes and no).

Dependent variable: To measure sexual assault risk factor knowledge, a posttest evaluation was conducted using the Gender-Specific Barriers to Bystander Behavior Items (Burns, 2009) and the College Date Rape Attitude Survey (Lanier \& Green, 2006). As some participants failed to complete one question, there was a need to compute an average of the response, before computing the scores of both tests, a reverse coding procedure was performed on the College Date Rape Attitude Survey (Lanier \& Green, 2006) for questions 1 through 7, 10 through 19, and 24; the result of this procedure is a test score that is the sum of the items and ranges from 1 to 120 . For the Gender-Specific Barriers to Bystander Behavior Items (Burns, 2009) the test score ranges form 1 to 126 .

Independent variable: The independent variable corresponds to group membership where 1 means treatment group and 0 means control group; the independent variable is a binary categorical variable.

\section{Qualitative measures}

An additional three qualitative questions were included in the online survey to assess the quality and impact of the intervention among the treatment group (Appendix 3).

\section{Analysis}

SPSS software was used for analyzing the data set. After collecting the data, the usability and completeness were checked. A reliability test of the measures used in this study was conducted for Gender-Specific Barriers to Bystander Behavior Items 
(Burns, 2009) with a Cronbach's alpha for the total sample of .90. The College Date Rape Attitude Survey (Lanier \& Green, 2006) with a Cronbach's alpha for the total sample of .63, which is below the usual threshold of .70.

To ensure comparability between the two groups, an independent-sample t-test was conducted on age between treatment and control participants. The results show no significant difference between the groups mean age, $t(75)=-.40, p=.68$. The same statistical analysis was conducted for gender between the two groups (treatment and control) and the result show no significant difference, $t(75)=.07, p=.93$. Descriptive statistics are presented among the treatment and control group in table 1.

A two-tailed two sample t-test analysis was performed with each measure as a dependent variable and the intended treatment as the independent variable. The analysis was made for the total population and also separately by gender, year in college and dating status. Also, a one tailed t-test was performed to evaluate the hypothesis. Finally, qualitative data were analyzed with themes identified in each question.

\section{Results}

\section{Description of the sample}

The final sample consisted of 76 undergraduate students. The majority $(88.8 \%)$ of the participants are 20 years old and the rest of the subjects are between 21 to 26 years old. Also the majority of the sample identifies themselves as female (71\%). Additionally $68.4 \%$ of the sample subjects were freshmen, while $31.58 \%$ were seniors, juniors or sophomores. The participants in the program were primarily of white race/ethnicity (75\%) and 25\% identified themselves as non-white, which included, 
Asian, Black or African American, Hispanic/Latino and Multiracial. Also, $60.5 \%$ of participants described themselves as single, the rest of the sample was coded as dating that included dating and married/living together. Finally, participants were asked if they had been part of a sexual assault prevention class before and $57 \%$ of the sample answered Yes and $43 \%$ No.

\section{Hypothesis testing}

The difference between the mean score of the Gender-Specific Barriers to Bystander Behavior Items (Burns, 2009) among the treatment and control was not statistically significant under a two-tailed two sample t-test ( $m$ diff $=3.25, p=0.34)$. Similarly, the difference between the mean score of the College Date Rape Attitude Survey (Lanier \& Green, 2006) among the treatment and control was not statistically different from zero $(m$ diff $=1.92, p=0.27)$ under a two-tailed two sample t-test.

A one-tailed two sample t-test was also performed. Again the mean difference between the treatment and control for the Gender-Specific Barriers to Bystander Behavior Items (Burns, 2009) measure was not statistically significant $(m$ diff $=3.25, p$ $=0.17)$. Similarly the mean difference in the College Date Rape Attitude Survey (Lanier \& Green, 2006) measure between treatment and control was not statistically significant $(m$ diff $=1.92, p=0.13)$. Hence the hypothesis is that the impact is less than or equal to zero cannot be rejected (although at a lower significance level than the two-tailed two sample t-test).

Next, the possible impact of the campaign on the different subgroups of interest in the sample was explored. Only one difference was found. The mean score of the College Date Rape Attitude Survey (Lanier \& Green, 2006) was 4.8 points higher for the treatment as compared to the control group, for those participants who 
did not receive a sexual assault prevention class before, though the level of significance can be considered small or marginal, $m$ diff $=4.81, p=0.09$. The mean scores of both the treatment and control subjects were not different from zero in the following subgroups: female, male, freshmen, no freshmen, dating, single, and previous sexual assault prevention class and no prevention classes.

In addition to the survey, participants were asked three open-ended questions to assess the quality of the intervention. The questions were the following: Was your experience with the text message positive or negative? Please explain, what did you learned from the text message intervention? Please explain, and did you share the information or forward the text message with someone? If Yes, with who and why?

Participants who received the text messages rated this experience as positive (74\%), $6 \%$ rated this experience as negative and the rest of the population rated as either neutral or no answer (20\%). In terms of what they learned with the intervention, $21 \%$ stated "a lot", $45 \%$ "somewhat", $32 \%$ "a little", and 2\% stated "nothing."

From the qualitative questions, three main themes emerged: learned new and useful information, learned specific strategies to prevent sexual assault, and intervention experience. In the first theme, learn new and useful information, participants found that the information provided in the text messages was useful. For example some of them mentioned that the intervention: "Opened my eyes on the subject". Participants reported being more conscious about risk factors after receiving the text messages: "I learned a lot about sexual assault that I didn't know beforehand was very surprised when I read the stats" and "it gave me information about a very important topic". This is an interesting result because this was one of the objectives of 
the intervention, to increase awareness among the students. Also, participants stated that they benefited from learning new information about sexual assault: "I learned that sexual assault is a much larger problem in today's society than I previously thought" and "I learned many facts about sexual assault that I did not know before". Being aware of the incidence of sexual assault may help the participants to be more alert. These results seem consistent with the PMT theory, in particular with the "perception of the threat" part, as the participants were able to learn new information about sexual assault.

The second theme was learn specific strategies to prevent sexual assault. Participants mentioned: "I felt more informed especially if I were single and had to think more carefully about who I brought home." This statement is consistent with the statistics about sexual assault and the text messages sent in the campaign. Also another participant mentioned: "positive it let me know more about what I can do during situations in which this occurs." This is important, as this suggest participants may incorporate the text message information into their lives. Similarly, participants seem more confident with the information provided as shown by the following quotes: "It gave me some reassurance that if a situation like that were to occur people would be there to talk to" and "It provided me with facts and ways to prevent sexual assault." In addition participants mentioned the importance of bystander intervention and care for victims: "I learned that it is important to help those who have been through such experiences and to get help from professionals when it is necessary". This theme is related to PMT in the "coping efficacy" as participants were able to connect the information provided in the intervention to possible sexual assault situations. 
Finally participants mentioned that their intervention experiences were: "the timing of the text messages were consistent and I wasn't bombarded with messages" and "The text messages weren't annoying and they provided some surprising facts". This information is important because it shows a potential desirable feature of the text message campaign, namely that its frequency and content is appropriate and provided a positive experience. Participants found the resources in the text messages important, as they were informative and provide new resources for them and friends in case they need it: "I learned that there are a lot more outlets available than I knew of" and "There are many places to call for help support or information about this subject".

Participants also were asked about whether they forwarded the text messages and to whom. Overall, $12.3 \%$ of the population mentioned that they forwarded the text messages to other people in their contact list, with $80 \%$ forwarding texts to their friends and the other $20 \%$ forwarding texts to their parents.

\section{Discussion and Implications}

The analysis did not support the hypothesis that the text message campaign had an impact on awareness of sexual assault in the population of interest. The lack of impact of the text message campaign on the Gender-Specific Barriers to Bystander Behavior Items (Burns, 2009) and on the College Date Rape Attitude Survey (Lanier \& Green, 2006) stands in contrast to previous findings in the literature that used alternative means of diffusion of information. The closest study to this is the "Take Care" evaluation by Kleinsasser et al., 2015 that had a sample of 93 subjects and found an impact in the Bystander Behavior Scale at .05 significance level. These results suggest that the text message campaign is less effective than the "Take Care" 
program in terms of changing test scores on the measures of interest. Another feature of the "Take Care" program was that the sample consisted of social psychology students, which make the results comparable to those presented in this paper. The literature also suggests that other interventions based on workshops, videos and conferences had positive impact on sexual assault awareness. The lack of impact of the text message based campaign suggests that even if it is low cost and easy to deliver, it may have limited effectiveness to change the existing knowledge of the subjects..

The convenience sample consisted of psychology students who possibly were already informed about the sexual assault risk factors. This could mean that the students already knew much of the information provided in the text messages, which reduces the text message campaign information value for them. A piece of evidence to support the previous statement comes from the exploratory analysis of the subgroup population. In particular, there is some evidence that the text message campaign positively influenced the test scores for those subjects who had not attended a sexual assault prevention class before. Therefore, it is possible that text message campaigns may work better in certain subpopulations, though more research is needed to support this hypothesis. Students who had not attended a sexual assault class before improved their mean score in the College Date Rape Attitude Survey (Lanier \& Green, 2006) by 4.81 points out of 120 points, which corresponds to an increase of $4 \%$. This stands out in contrast to the absence of impact of the treatment on the same dependent variable for the subgroup that did received a sexual assault class before. This can be interpreted as a result of the differential of knowledge between the groups that did receive and did 
not receive the sexual assault class before. It seems that those subjects with a lower initial level of knowledge of sexual assault awareness benefited the most form the text message campaign with respect to this measure. A remark is in order about this finding; the impact was statistically significant only at the $p<.10$, a marginal effect.

Less conclusive evidence was found for the subgroup of subjects who did receive a sexual assault class on the Gender-Specific Barriers to Bystander Behavior Items (Burns, 2009) measure. There was a numerical improvement of the mean score (8.25 points out of 126 points), which corresponds to an increase of $6.5 \%$. However the significance level in this case was slightly above the .10 threshold.

The close to significant impact on the population that did not receive a sexual assault class before is interesting because under the PMT a positive impact on College Date Rape Attitude Survey (Lanier \& Green, 2006) would be consistent with an increase in the "perception of threat" postulated by the PMT, due to receiving the text message campaign. This may only happen for those individuals who were most likely to be unaware about sexual assault risk factors. The subjects who improved in terms of "perception of threat" did not improve on "coping efficacy" as measured by scores on the Gender-Specific Barriers to Bystander Behavior Items (Burns, 2009).

However, some positive themes were reported by the subjects in the treatment group including that they learned from the text message campaign, that their experience was in general positive, and positive feelings were associated with the content and delivery of the campaign. These results are encouraging in terms of providing a positive learning experience for the subjects, suggesting that text messages maybe a practical way to deliver this information among young adults. However, the 
modest rate in learning experience may explain why there was no impact in the whole sample, as some participants could know this information before the intervention.

The primary limitation of the intervention was the high number of subjects who did not complete the online survey, which was close to $50 \%$ (considered as dropouts). This directly reduced the power of the study due to smaller number of observations. It must be underlined that the dropout rate did not differ among the treatment and the control groups, which supports the idea that the dropout rate was random and not related to the treatment.

Another limitation is the use of a convenience sample. Participants were part of a psychology class. This group is not representative of the general college population. For instance, the gender composition of the psychology class is biased towards the female population with $71 \%$ in comparison to the general URI population with $54 \%$ female students (University of Rhode Island | Best College | US News. 2016). This shows that the psychology class is not a random sample of college students. The majority $(57 \%)$ of the sample received a sexual assault prevention class before the text message intervention. Some subjects in the qualitative analysis reported that they already knew the information; this point has to be further explored by studying a truly representative sample of the college population.

The third limitation is the low Cronbach's alpha $(a=.63)$ for the GenderSpecific Barriers to Bystander Behavior Items (Burns, 2009), that is below the threshold of .70. Because the reliability of the measure is low, this reduces the correlation between the questions and what the test is actually measuring (construct of interest). 
The fourth limitation is the lack of a short-term follow-up impact evaluation of the intervention. An interesting follow-up from this study could be to retest the subjects in the future to measure the impact of this intervention in the long-term.

The last limitation of the study is that the use of many individual tests increases the likelihood of finding a significant outcome that may be due solely to chance, as in the case of the result found in the College Date Rape Attitude Survey (Lanier \& Green, 2006). For future analysis, a regression could help to explore the data in more detail.

This study does not support the use of text message based campaigns for sexual assault prevention on college campuses, because it has no significant impact in the overall population and subgroups of interest. The measures used in this study may need to be reconsidered as they do not measure behavioral change, only the willingness to intervene. The inclusion of weekly diary entries may provide more information about the impact of the intervention on the participants.

To the best of my knowledge, this is the first text message campaign to attempt to increase awareness about sexual assault on college campuses. For that reason, it opens a door to new studies analyzing the impact of text messages to fight against sexual assault on campus. Text message campaigns may be used as boosters for one time in person interventions, to possible improve long-term effects. 
Appendix 1 Gender-Specific Barriers to Bystander Behavior (Burns, 2009)

Answer the following question were 1=Strongly Disagree, 2=Disagree, 3=Somewhat Disagree, 4=Neither Agree nor Disagree, 5=Somewhat Agree, 6=Agree, 7= Strongly Agree .

\begin{tabular}{|c|c|c|c|c|c|c|}
\hline \multirow{2}{*}{$\begin{array}{l}\text { Gender-Specific Barriers to Bystander Behavior (Burns, 2009) } \\
\text { 1. To reduce sexual assault risk, I never leave a friend alone at a party or } \\
\text { bar even if the friend insists she'll be alright. }\end{array}$} & 1 & 2 & 3 & 4 & 5 & 6 \\
\hline & & & & & & \\
\hline $\begin{array}{l}\text { 2. I try to be a good friend by not letting my intoxicated female friends } \\
\text { go to a private location with a guy. }\end{array}$ & & & & & & \\
\hline $\begin{array}{l}\text { 3. To reduce sexual assault risk, I discourage my friends from going to a } \\
\text { private location with a male acquaintance. }\end{array}$ & & & & & & \\
\hline $\begin{array}{l}\text { 4. I remind my female friends to take actions to reduce sexual } \\
\text { assault risk. }\end{array}$ & & & & & & \\
\hline $\begin{array}{l}\text { 5. If I see a man pressuring a woman to leave a party or bar with him, } \\
\text { I intervene. }\end{array}$ & & & & & & \\
\hline $\begin{array}{l}\text { 6. If I see a situation in which it looks like someone will end up being } \\
\text { taken advantage of sexually, I intervene. }\end{array}$ & & & & & & \\
\hline $\begin{array}{l}\text { 7. If I see someone "putting the moves" on a person that is very } \\
\text { intoxicated, I say or do something about it. }\end{array}$ & & & & & & \\
\hline $\begin{array}{l}\text { 8. If I hear someone making inappropriate sexual comments to } \\
\text { someone else, I say or do something about it. }\end{array}$ & & & & & & \\
\hline $\begin{array}{l}\text { 9. To keep my friends out of trouble, I stop them from doing things } \\
\text { that might meet the definition of sexual assault. }\end{array}$ & & & & & & \\
\hline $\begin{array}{l}\text { 10. I intervene if I see a friend trying to take advantage of someone's } \\
\text { intoxicated state to have sex with them. }\end{array}$ & & & & & & \\
\hline $\begin{array}{l}\text { 11. I say something if I hear a friends talking about getting someone } \\
\text { intoxicated to have sex with them. }\end{array}$ & & & & & & \\
\hline $\begin{array}{l}\text { 12. I discourage my friends from talking about women in sexually } \\
\text { degrading ways. }\end{array}$ & & & & & & \\
\hline $\begin{array}{l}\text { 13. I will interfere with another guy's "action" if I think it might stop } \\
\text { them from possibly committing a sexual assault. }\end{array}$ & & & & & & \\
\hline $\begin{array}{l}\text { 14. I intervene if I see a stranger or acquaintance trying to take } \\
\text { advantage } \\
\text { of someone's intoxicated state to have sex with them. }\end{array}$ & & & & & & \\
\hline $\begin{array}{l}\text { 15. I say something if I hear a stranger or acquaintance talking about } \\
\text { taking sexual advantage of someone's intoxicated state. }\end{array}$ & & & & & & \\
\hline $\begin{array}{l}\text { 16. I discourage strangers or acquaintances if I hear them talking about } \\
\text { women in sexually degrading ways. }\end{array}$ & & & & & & \\
\hline $\begin{array}{l}\text { 17. I am more likely to intervene to prevent sexual assault if I know the } \\
\text { potential victim than if I do not. }\end{array}$ & & & & & & \\
\hline $\begin{array}{l}\text { 18. I am more likely to intervene to prevent sexual assault if I know the } \\
\text { potential perpetrator than if I do not. }\end{array}$ & & & & & & \\
\hline
\end{tabular}


Appendix 2 College Date Rape Attitude Survey (Lanier \& Green, 2006)

Please answer the following question were: $1=$ strongly agree, $2=$ agree, $3=$ neutral, $4=$ disagree and $5=$ strongly disagree

\begin{tabular}{|c|c|c|c|c|c|}
\hline College Date Rape Attitude Survey & 1 & 2 & 3 & 4 & 5 \\
\hline $\begin{array}{l}\text { 1. I believe that talking about sex destroys the romance of that particular } \\
\text { moment }\end{array}$ & & & & & \\
\hline 2. Most women enjoy being submissive in sexual relations & & & & & \\
\hline 3. If a woman dresses in a sexy dress she is asking for sex & & & & & \\
\hline $\begin{array}{l}\text { 4. If a person asks a man out on a date then she is definitely interested in having } \\
\text { sex }\end{array}$ & & & & & \\
\hline $\begin{array}{l}\text { 5. In the majority of date rape the victim is promiscuous and has a bad } \\
\text { reputation }\end{array}$ & & & & & \\
\hline $\begin{array}{l}\text { 6. A person is entitle to intercourse if his partner has agree to it but at the last } \\
\text { moment changed her mind }\end{array}$ & & & & & \\
\hline $\begin{array}{l}\text { 7. Many people pretend they don't want to have sex because they don't want to } \\
\text { appear "easy" }\end{array}$ & & & & & \\
\hline 8. A person can control his behavior no matter how sexually arouse he feels & & & & & \\
\hline 9. I believe that alcohol and other drugs affect my sexual decision making & & & & & \\
\hline $\begin{array}{l}\text { 10. The degree of a person's resistance should be a major factor in determining } \\
\text { if a rape has occurred }\end{array}$ & & & & & \\
\hline 11. When a person says "no" to sex what she really means is "maybe" & & & & & \\
\hline $\begin{array}{l}\text { 12. If a person lets a man buy her dinner or pay for a movie or drinks, she owes } \\
\text { him sex }\end{array}$ & & & & & \\
\hline 13. People provoke rape by their behaviors & & & & & \\
\hline 14. People often lie about being raped to get back at their dates & & & & & \\
\hline $\begin{array}{l}\text { 15. It is okay to pressure a date to drink alcohol in order to improve ones } \\
\text { chances of getting ones date to have sex }\end{array}$ & & & & & \\
\hline $\begin{array}{l}\text { 16. When a person asks her date back to her place, I expect that something } \\
\text { sexual will take place }\end{array}$ & & & & & \\
\hline $\begin{array}{l}\text { 17. Date rapists are usually motivated by overwhelming, unfulfilled sexual } \\
\text { desire }\end{array}$ & & & & & \\
\hline 18. In most cases when a women was raped she was asking for it & & & & & \\
\hline 19. I stop the first time my date says "no" to sexually activity & & & & & \\
\hline 20. I have sex when I am intoxicated & & & & & \\
\hline 21. I have sex when my partner is intoxicated & & & & & \\
\hline 22. When I want to touch someone sexually I try it and see how they react & & & & & \\
\hline $\begin{array}{l}\text { 23. I wont stop sexually activity when asked to if I am already } \\
\text { sexually aroused }\end{array}$ & & & & & \\
\hline 24. When I hear a sexiest comment I ind & & & & & \\
\hline
\end{tabular}


Appendix 3 Demographics

The first group of questions are general information question. Please answer the question according what is required

1) Year of birth:

2) I identify my sex as: $\quad \square$ Female $\quad \square$ Male $\quad \square$ Other

3) Year in college: $\square$ Freshmen $\quad \square$ Sophomore $\quad \square$ Junior $\quad \square$ Senior

4) Primary Race/Ethnicity:

$\square$ American Indian or Alaska Native

$\square$ Asian

$\square$ Black or African American

$\square$ Hispanic/Latino

$\square$ Native Hawaiian or other Pacific Islander

$\square$ White

$\square$ Multiracial

$\square$ Other

5) Where do you live

$\square$ On campus $\quad \square$ Parents house $\quad \square$ Greek housing $\quad \square$ Off campus $\quad \square$ Other

6) Do you consider yourself socially active? $\quad \square$ Yes $\square$ No

7) Would you describe yourself as:

$\square$ Single $\quad \square$ Dating $\quad \square$ Married/Living together $\quad$ Divorced $\quad \square$ Widowed

口Other

8) Have you ever participated in a sexual assault prevention class before? (Check all that apply)

$\square$ No 
$\square$ Yes, at church

$\square$ Yes, at URI 101

$\square$ Yes, URI bystander program

$\square$ Yes, URI online intervention

$\square$ Yes, home

$\square$ Yes, high school

$\square$ Yes, other

9) Did you receive a text message about sexual assault prevention during the last 4 weeks?

$\square$ Yes $\square$ No $\quad \square$ Don’t know

If Yes, answer the following questions

10) How much did you learn with the text message intervention? Would you say

$\square$ Nothing $\quad \square$ A little $\quad \square$ Somewhat $\square$ A lot

11) Was your experience with the text messages positive or negative? Please Explain

12) What did you learn from the text message intervention? Please Explain:

13) Did you share the information or forward the text message with someone?

14) If Yes, with who, and why? 


\section{Appendix 4 IRB Approval}



Thank you for your submission of Revision materials for this research study. The University of Rhode Island IRB has APPROVED your submission. This approval is based on an appropriate risk/benefit ratio and a study design wherein the risks have been minimized. All research must be conducted in accordance with this approved submission.

This submission has received Expedited Review based on the applicable federal regulation 45 CFR 46 and 21 CFR $50 \& 56$.

Please note that any revision to previously approved materials must be approved by this office prior to initiation. Please use the appropriate revision forms for this procedure.

All SERIOUS and UNEXPECTED adverse events must be reported to this office. Please use the appropriate Appendix S - Event Reporting for this procedure. All FDA and sponsor reporting requirements must be followed.

Please report all NON-COMPLIANCE issues or COMPLAINTS regarding this study to this office. Please note that all research records must be retained for a minimum of five years after the project ends.

Based on the risks, this project requires Continuing Review by this office by January 5, 2017. Please use the CONTINUING REVIEW FORM for this procedure. 
If you have any general questions, please contact us by email at researchinteqrity@etal.uri.edu. For study related questions, please contact us via project mail through IRBNet. Please include your study title and reference number in all correspondence with this office.

Please remember that informed consent is a process beginning with a description of the study and insurance of participant understanding followed by a signed consent form. Informed consent must continue throughout the study via a dialogue between the researcher and research participant. Federal regulations require each participant receive a copy of the signed consent document unless the signature requirement has been waived by the IRB.

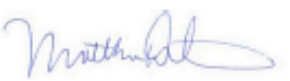

Matthew Delmonico, Ph.D., MPH

IRB Chair 


\section{Appendix 5 Informed Consent}

THE

\section{UNIVERSITY}

OF RHODE ISLAND

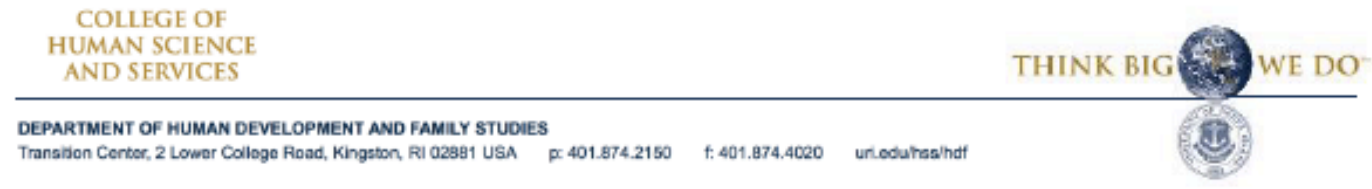

The University of Rhode Island

Department of Human Development and Family studies

2 Lower College Road, Kingston, RI 02881. Transition Center

A text message intervention to increase awareness of sexual assault on campus

\section{CONSENT FORM FOR RESEARCH}

You have been invited to take part in a research project described below. The researcher will explain the project to you in detail. You should feel free to ask questions. If you have more questions later, you may contact Karen McCurdy, the person mainly responsible for this study, at 401-874-5960. You may also contact the student research, Ximena Chiriboga, at 401-497-9861. You must be at least 18 years old and under the age of 27 to be in this research project. You must also have a personal cell phone capable of receiving text messages. Anyone under the age of 18 and over the age of 26 , or without access to a personal cell phone, will be given an alternative assignment. Anyone choosing not to participate will also have alternative research options.

Description of the project:

PSY 113 students are invited to participate in this study that will evaluate the impact of a text message campaign to increase awareness about sexual assault on campus. The intervention, including the assessment, will have a length of 5-weeks; the total time for completing this research will be 15 to 30 minutes.

What will be done:

If you decide to take part in this study, here is what will happen. You will complete the attached page which asks for your cell phone number. This page will be separated from this consent form. Participants can receive up to 2 text messages per week, for 4 weeks. Standard text messaging rates may apply for those who do not have unlimited texting. After the fourth week, participants will be asked to complete an online evaluation that should take between 15-20 minutes.

Risks or discomfort:

Few risks or discomforts are expected to occur from this research study. If you feel uncomfortable at any time during the length of the study, you may unsubscribe from the text message campaign. The questions that you need to complete at the end of the study may cause you discomfort and you may chose not to answer any or all of the questions.

If this study causes distress, you could also contact Dr. Karen McCurdy at kmccurdy@uri.edu.

Benefits of this study:

By taking part of this study, you could learn about risk factors for sexual assault and available sexual assault prevention resources.

THE

UNIVERSITY IRB $t$ HU1516-100

OF RHODE ISLAND IRB Approval Dote 01/06/2016

PIVISION OF RISEARCH IRB Approval Expiration 01/05/2017 
Confidentiality:

Your part in this study is confidential. Your informed consent form will be kept separate from your cell phone number and the information collected. None of the collected information will identify you by name or any other identifier. The informed consent and collected information will be stored in 2 separate locked file cabinets at Dr. Karen McCurdy's office for three years following the completion of the study. The page with your cell phone number will be destroyed upon after the first text messages are successfully sent. Your name will never be associated with your data. Dr. McCurdy's office is located at 2 Lower College Road, Transition Center, Kingston, RI 02881. Data will be available only to Ximena Chiriboga and Dr. Karen McCurdy. Your research data will also be used in future data analysis and publication. This means your research data, which will never be identifiable by name, will be analyzed as part of a larger dataset and presented at national conferences or in academic journals.

Decision to quit at any time:

The decision to take part in this study is up to you. You do not have to participate. If you decide to take part in the study, you may quit at any time. Whatever you decide will in no way affect your grade or status as a student

Rights and Complaints:

If you are not satisfied with the way this study is performed, you may discuss your complaints with Ximena Chiriboga at xchiriboga@uri.edu or with Dr. Karen McCurdy at kmccurdy@uriedu, anonymously, if you choose. In addition, if you have questions about your rights as a research participant, you may contact the office of the Vice President for Research and Economic Development, 70 Lower College Road, Suite 2, University of Rhode Island, Kingston, Rhode Island, telephone: (401) 874-4328.

You have read the Consent Form. Your questions have been answered. Your signature on this form means that you understand the information and you agree to participate in this study.

Signature of Participant

Typed/printed Name

Date
Signature of Researcher

Typed/printed name

Date

Please sign both consent forms, keeping one for yourself

Please complete the following page.

THE
IRB + HU1516-100 IRB Approval Date 01/06/2016 IRB Approval Expiration 01/05/2017 
If you have decided to participate in this research, please write your cell phone number below. There will be no charges associated with receipt of any text message.

(Area Code) Phone number

THE

UNIVERSITY IRBเHU1S16-100

IRB Approval Date 01/06/2016

OF RHODE ISLAND
DIVSION OF RISEARCH IRB Approval Expiration 01/05/2017

IND LCONOMT 
Table 1 Descriptive statistics

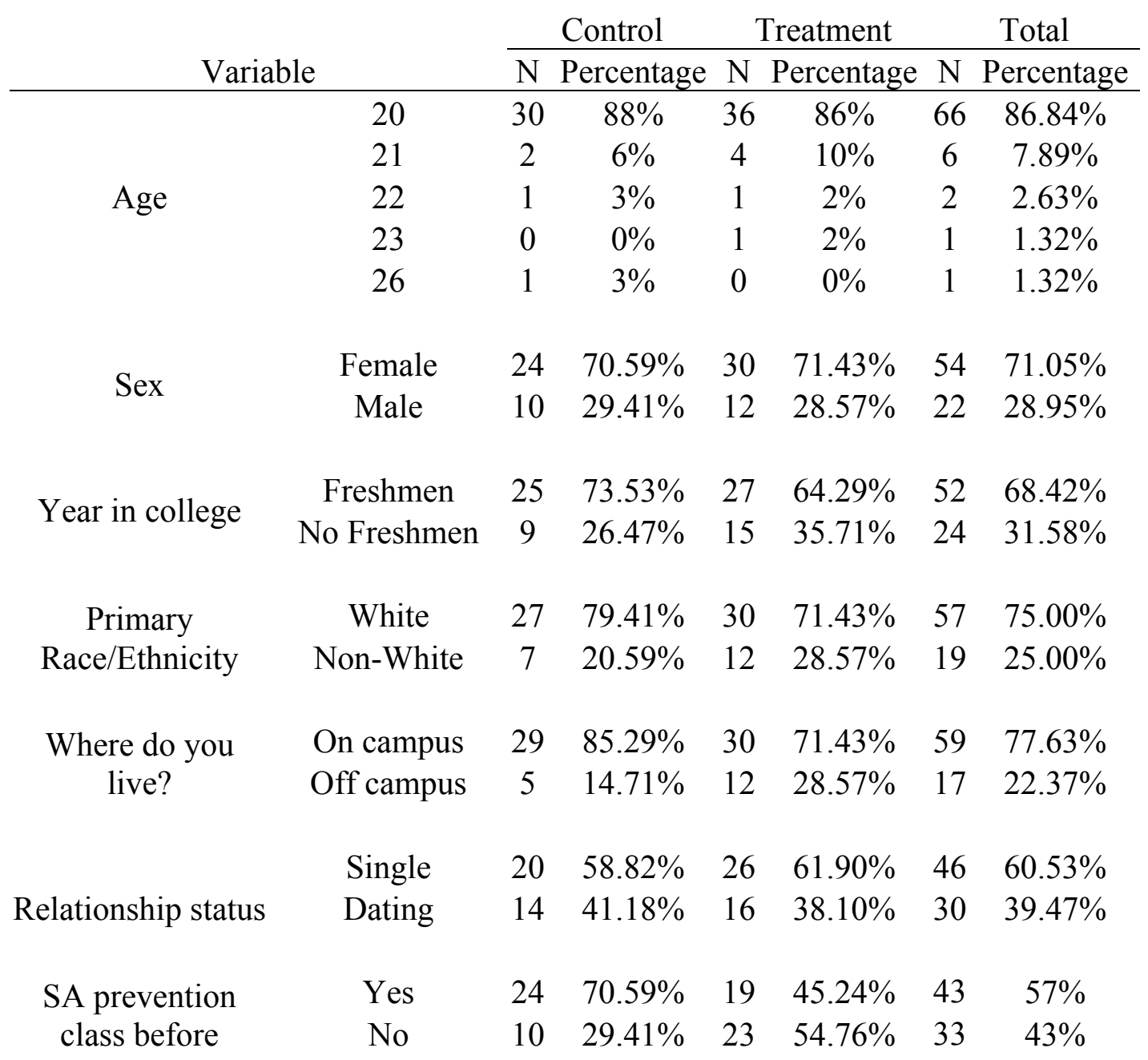


Table 2 Treatment vs Control

Gender-Specific Barriers to Bystander Behavior Items (Burns, 2009)

\begin{tabular}{lcccccc} 
& $\mathrm{n}$ & Mean & $\mathrm{SD}$ & $\mathrm{t}$ & $\begin{array}{c}p \text { two- } \\
\text { tailed } t- \\
\text { test }\end{array}$ & $\begin{array}{c}p \text { one- } \\
\text { tailed } t- \\
\text { test }\end{array}$ \\
\hline $\begin{array}{l}\text { Treatment } \\
\text { Control }\end{array}$ & 34 & 105.04 & 13.98 & 0.95 & 0.343 & 0.17 \\
& 42 & 101.79 & 15.71 & & &
\end{tabular}

College Date Rape Attitude Survey (Lanier \& Green, 2006)

\begin{tabular}{lcccccc} 
& $\mathrm{n}$ & Mean & $\mathrm{SD}$ & $\mathrm{t}$ & $\begin{array}{c}p \text { two- } \\
\text { tailed } t-\end{array}$ & $\begin{array}{c}p \text { one- } \\
\text { tailed } t-\end{array}$ \\
test & & test \\
\hline Treatment & 34 & 57.71 & 6.98 & 1.1 & 0.27 & 0.13 \\
Control & 42 & 55.79 & 8.2 & & &
\end{tabular}


Table 3 Analysis of the impact of the intervention



$*_{\mathrm{p}}<.10$ 


\section{Reference}

Amar, A. F., Sutherland, M., \& Laughon, K. (2014). Gender differences in attitudes and beliefs associated with bystander behavior and sexual assault. Journal of forensic nursing, 10(2), 84-91

Anderson, L. A., \& Whiston, S. C. (2005). Sexual assault education programs: A meta-analytic examination of their effectiveness. Psychology of Women Quarterly, 29(4), 374-388.

Banyard, V. L., Moynihan, M. M., \& Crossman, M. T. (2009). Reducing sexual violence on campus: The role of student leaders as empowered bystanders. Journal of College Student Development, 50(4), 446-457.

Breitenbecher, K. H. (2001). Sexual assault on college campuses: Is an ounce of prevention enough?. Applied and Preventive Psychology, 9(1), 23-52.

Burn, S. M. (2009). A situational model of sexual assault prevention through bystander intervention. Sex Roles, 60(11-12), 779-792.

Cantor, D., \& Fisher, W. B. (2015). Report on the AAU Campus Climate Survey on Sexual Assault and Sexual Misconduct Assault.

Cocosila, M., Archer, N., Haynes, R. B., \& Yuan, Y. (2009). Can wireless text messaging improve adherence to preventive activities? Results of a randomized controlled trial. International journal of medical informatics, $78(4), 230-238$.

Cooper, M. L. (2002). Alcohol use and risky sexual behavior among college students and youth: Evaluating the evidence. Journal of Studies on Alcohol, supplement, (14), 101-117. 
Dawson, D. A., Grant, B. F., Stinson, F. S., \& Chou, P. S. (2004). Another look at heavy episodic drinking and alcohol use disorders among college and noncollege youth. Journal of studies on alcohol, 65(4), 477-488.

Fisher, B. S., Cullen, F. T., \& Turner, M. G. (2000). The Sexual Victimization of College Women. Research Report.

Fjeldsoe, B. S., Marshall, A. L., \& Miller, Y. D. (2009). Behavior change interventions delivered by mobile telephone short-message service. American journal of preventive medicine, 36(2), 165-173.

Force, W. H. T. (2014). Not alone: The first report of the White House task force to protect students from sexual assault.

Foubert, J. D., Langhinrichsen-Rohling, J., Brasfield, H., \& Hill, B. (2010). Effects of a rape awareness program on college women: Increasing bystander efficacy and willingness to intervene. Journal of Community Psychology, 38(7), 813827.

Floyd, D. L., Prentice-Dunn, S., \& Rogers, R. W. (2000). A meta-analysis of research on protection motivation theory. Journal of applied social psychology, 30(2), 407-429.

Gold, J., Lim, M. S., Hellard, M. E., Hocking, J. S., \& Keogh, L. (2010). What's in a message? Delivering sexual health promotion to young people in Australia via text messaging. BMC public health, 10(1), 792.

Hall, A. K., Cole-Lewis, H., \& Bernhardt, J. M. (2015). Mobile text messaging for health: a systematic review of reviews. Annual review of public health, 36, 393. 
Kleinsasser, A., Jouriles, E. N., McDonald, R., \& Rosenfield, D. (2015). An online bystander intervention program for the prevention of sexual violence. Psychology of violence, 5(3), 227.

Krebs, C. P., Lindquist, C. H., Warner, T. D., Fisher, B. S., \& Martin, S. L. (2007). The campus sexual assault (CSA) study. Washington, DC: National Institute of Justice, US Department of Justice.

Lanier, C. A., \& Green, B. A. (2006). Principal Component Analysis of the College Date Rape Attitude Survey (CDRAS) An Instrument for the Evaluation of Date Rape Prevention Programs. Journal of aggression, maltreatment \& trauma, 13(2), 79-93.

Maddux, J. E., \& Rogers, R. W. (1983). Protection motivation and self-efficacy: A revised theory of fear appeals and attitude change. Journal of experimental social psychology, 19(5), 469-479..

Obermayer, J. L., Riley, W. T., Asif, O., \& Jean-Mary, J. (2004). College smokingcessation using cell phone text messaging. Journal of American College Health, 53(2), 71-78.

Pechmann, C., Zhao, G., Goldberg, M. E., \& Reibling, E. T. (2003). What to convey in antismoking advertisements for adolescents: The use of protection motivation theory to identify effective message themes. Journal of Marketing, $67(2), 1-18$

Prentice-Dunn, S., Mcmath, B. F., \& Cramer, R. J. (2009). Protection motivation theory and stages of change in sun protective behavior. Journal of Health Psychology, 14(2), 297-305. 
Schwartz, R. H., Milteer, R., \& LeBeau, M. A. (2000). Drug-facilitated sexual assault ('date rape'). Southern medical journal, 93(6), 558-561.

Sinozich, S., \& Langton, L. (2014). Rape and sexual assault victimization among college-age females, 1995-2013. US Department of Justice, Office of Justice Programs, The Bureau of Justice Statistcs. Full text available at http://www. bjs. gov/content/pub/pdf/rsavcaf9513. pdf.

Smith, A., Rainie, L., \& Zickuhr, K. (2011). College students and technology. Pew Internet \& American Life Project, 19, 2011.

Söchting, I., Fairbrother, N., \& Koch, W. J. (2004). Sexual Assault of Women Prevention Efforts and Risk Factors. Violence Against Women, 10(1), 73-93. University of Rhode Island | Best College | US News. (2016). Colleges.usnews.rankingsandreviews.com. Retrieved 6 June 2016, from http://colleges.usnews.rankingsandreviews.com/best-colleges/university-of$\underline{\text { rhode-island-3414 }}$ 